\title{
MODEL TRANSSHIPMENT GUNA MENGHASILKAN BIAYA PENDISTRIBUSIAN YANG MINIMUM MELALUI KAJIAN TEORITIS
}

\author{
Ayudina Puji $\mathbf{E}^{1}$, Mirna Widayanti ${ }^{2}$
}

\begin{abstract}
PR . Karya Timur, Malang is an Industrial Cigarettes which be productive cigarette with Harmonis brand for East Java marketing area, Horizon Super Filter and Horizon Mild Filter for marketing area beyond Java. This research only analized for east java marketing area. This company make use of two (2) source to meet every marketing area needs which is allocated directly through those two source on condition that each sources allocated in accordance with request for every marketing area. It is surely needs a lot of cost, because each sources still had to supply for every marketing area. This research on it's own was submitted to examine a better distribution system so it can minimize cost of distribution.

Transshipment model is one of a model that we are using to planning distribution system. With analysis that a source become destination and on the contrary a destination can be source too. Analysis begin by forecasting, using Trend Linier Method and Trend Eksponensial Method. The making use of this method based on smallest result of MAPE to forecast marketing schedule for Mei 2001 - Juli 2002. Furthermore analysis distribution calculation using VAM and MODI method with QS program assistance.

Before we analized with Transshipment model, total cost that we have to spent money on distribution system are Rp 249.932.400,- , and after we using Transshipment model analysing it gave suggestion distribution system with total cost are $\mathrm{Rp} 210.537 .504$,- , So economizing that we had are $\operatorname{Rp} 39.394 .896,-$.
\end{abstract}

Key Words : Transportation, Transshipment, QS program

\section{PENDAHULUAN}

\begin{abstract}
Masalah transportasi salah satu masalah serius yang sering dihadapi perusahaan karena tidak adanya koordinasi dalam pengiriman barang. Sehingga memungkinkan terjadinya pembengkakan biaya pengiriman. Oleh karena itu perlu dilakukan suatu usaha agar biaya pengiriman seminimal mungkin.
\end{abstract}

PR. Karya Timur Malang adalah perusahaan rokok yang selain memproduksi merek Harmonis untuk daerah pemasaran Jawa Timur , merek Horizon Super Filter dan Horizon Mild Filter untuk daerah pemasaran Luar Jawa. , juga menangani pendistribusian produk rokok untuk tiap daerah pemasaran. Dalam memenuhi permintaan pasar perusahaan memiliki gudang dan divisi perwakilan yang menangani masalah pendistribusian produk. Dimana pola jalur distribusi yang ada saat ini belum optimal. Hal ini dikarenakan tiap gudang mengalokasikan produk untuk tiap divisi perwakilan, dimana wilayah pemasaranya memiliki jarak tempuh yang saling melewati.

Dengan demikian diperlukan analisa ulang untuk mengkaji optimalitas sistem distribusi dari sumber dan tujuan yang ada dengan alternatif jalur untuk rute yang dilewati mampu meminimumkan biaya pengiriman. Sehingga untuk memenangkan

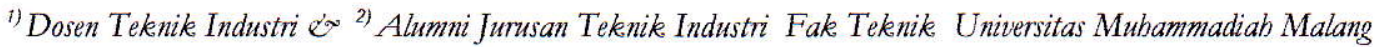


persaingan usaha sejenis pada proses pendistribusian dapat berjalan tepat sasaran.

\section{TINJAUAN PUSTAKA}

\section{Transportasi}

Transportasi adalah kegiatan pemindahan produk dari suatu tempat ke tempat lain. Fungsi dari transportasi adalah mengangkut barang dari produsen kepada konsumen. Tidak akan ada artinya produksi jika tidak tersedia jasa transportasi yang membawa hasil produksi tersebut sampai kepada konsumen.

\section{Pengertian Model Transportasi}

Model transportasi merupakan suatu model yang digunakan untuk pengaturan yang berhubungan dengan pelaksanaan pendistribusian suatu komoditas atau produk dari sumber - sumber yang menyediakan produk yang sama (supply), ke tempat-tempat yang membutuhkan secara optimal (demand, destination). Dalam arti sederhana, model transportasi berusaha menentukan sebuah rencana transportasi sebuah komoditas dari sejumlah sumber ke sejumlah tujuan.

Tujuan dari model transportasi itu sendiri adalah menentukan jumlah yang harus dikirimkan dari setiap sumber ke setiap tujuan sedemikian rupa sehingga biaya transportasi total diminimumkan.

Adapun ciri - ciri khusus model transportasi , yaitu :

1. Terdapat sejumlah sumber dan sejumlah tujuan tertentu.

2. Kuantitas komoditas atau produk yang didistribusikan dari setiap sumber dan produk yang dibutuhkan atau diminta oleh setiap tujuan, besarnya tertentu.

3. Komoditas atau produk yang dikirim atau diangkut dari suatu sumber ke suatu tujuan besarnya sesuai dengan permintaan dan atau kapasitas sumber.

4. Biaya transportasi komoditas suatu sumber ke suatu tujuan, besarnya tertentu.

Adapun data yang digunakan dalam model ini mencakup

1. Tingkat (jumlah) penawaran di setiap sumber dan jumlah permintaan di setiap tujuan.

2. Biaya transportasi per unit produk dari setiap sumber ke setiap tujuan.

Bila model transportasi digambarkan maka akan terdapat sebuah jaringan dengan $m$ sumber dan $n$ tujuan. Sebuah sumber atau tujuan diwakili oleh sebuah node.

Sedangkan busur yang menghubungkan sebuah sumber dan sebuah tujuan mewakili rute pengiriman produk tersebut. Jumlah penawaran di sumber $i$ adalah $a_{i}$ dan permintaan di tujuan $j$ adalah $b_{j}$. Biaya unit transportasi antara sumber $i$ dan tujuan $j$ adalah $C_{i j}$. Sedangkan Xij mewakili jumlah barang yang dikirimkan dari sumber i ke tujuan $\mathrm{j}$.

Maka formulasi dalam program linier sebagai berikut :

Meminimasikan :

$$
\mathrm{Z}=\sum_{i=1}^{m} \sum_{j=1}^{n} C_{i j} \mathrm{Xij}
$$


Dengan batasan :

$$
\begin{aligned}
& \sum_{j=1}^{n} X_{i j} \leq a_{i}, I=1,2, \ldots, m \\
& \sum_{i=1}^{m} X i j \geq b_{j}, j=1,2, \ldots, n
\end{aligned}
$$

$\mathrm{Xij}_{\mathrm{ij}} \geq 0, \quad$ untuk semua $\mathrm{i}$ dan $\mathrm{j}$

Dengan :

$$
\begin{aligned}
& \mathrm{Z}=\text { Fungsi Tujuan } \\
& \mathrm{a}_{\mathrm{I}}=\text { Kapasitas sumber ke (i) } \\
& \mathrm{b}_{\mathrm{j}}=\text { Kapasitas permintaan tujuan di }
\end{aligned}
$$

(j)

$$
C_{i j}=\text { Biaya transportasi per unit dari }
$$

sumber (I) ke tujuan (j)

$\mathrm{Xij}=$ Jumlah unit yang terkirim dari sumber (I) ke tujuan (j)

\section{Metode - metode Transportasi}

Adapun uraian dari metode-metode transportasi adalah sebagai berikut :

1. Penentuan Pemecahan Awal

North West-Corner

* Metode Least - Cost

* Metode Vogel's Approximation Method ( VAM)

2. Penentuan Solusi Optimal

Untuk memperoleh pemecahan yang optimum ada 2 cara yaitu :

* Metode Batu Loncatan (Stepping Stone)

* Metode MODI (Modified Distribution Method)

\section{Model Transhipment}

Model transhipment adalah model yang memungkinkan dilakukannya pengiriman komoditas secara tidak langsung, dimana barang dari suatu sumber dapat berada pada sumber lain atau tujuan lain sebelum mencapai tujuan akhir. Jadi pada model transshipment ini suatu sumber sekaligus dapat berperan sebagai tujuan dan sebaliknya, suatu tujuan dapat juga berperan sebagai sumber.

\section{Penerapan Model Transshipment}

Dalam model ini, setiap sumber ataupun tujuan dipandang sebagai titik titik potensial bagi demand maupun supply. Oleh karena itu untuk menjamin bahwa tiap titik potensial tersebut mampu menampung total produk disamping produk yang telah ada pada titik - titik tersebut, maka perlu ditambahkan kepada titik - titik itu kuantitas demand dan supplynya masing - masing sebesar $\mathbf{B}$.

Jumlah B biasanya dirujuk sebagai buffer, sebuah nilai yang cukup besar.

$$
\mathbf{B} \geq \sum_{i=1}^{m} a_{i}+\sum_{j=1}^{n} b_{j}
$$

\section{METODOLOGI PENELITIAN}

\section{Data yang Diperlukan}

Untuk melakukan analisa diperlukan datadata antara lain : data penjualan, Biaya pengiriman per unit, Kapasitas simpan, dan wilayah penjualan

\section{Tahap Pengolahan Data}

Untuk menganalisa data yang ada maka diperlukan tahapan sebagai berikut :

1. Metode Peramalan

2. Alokasi jumlah produk dan penentuan pola jalur distribusi awal 
3. Analisa dengan model transipment melalui program QS

4. Model Transportasi

* Metode VAM

Metode MODI

5. Analisa Sensitivitas

6. Perbandingan biaya awal dan biaya usulan

7. Optimum

8. Pola jalur distribusi usulan dengan biaya pengiriman minimal

\section{HASIL DAN PEMBAHASAN}

Peramalan Permintaan Bulan Mei 2002 Juli 2002

Untuk menghitung peramalan permintaan , penyusun menggunakan perhitungan secara manual kemudian diteruskan dengan program Minitab.

Dimana metode peramalan yang dipakai adalah metode Trend Linier dan metode Trend Eksponensial, karena data penjualan yang ada menunjukkan adanya peningkatan/trend dari bulan ke bulan berikutnya (ditunjukkan pada lampiran 4). Kemudian dipilih metode peramalan yang memiliki nilai MAPE terkecil.

Peramalan Menggunakan Metode Trend

Linier

$$
\mathrm{a}=\frac{\sum y^{\mathrm{Y}^{\prime}=\mathrm{a}+\mathrm{b} \cdot \mathrm{x}}}{n}, \quad \mathrm{~b}=\frac{\sum x y}{\sum x^{2}}
$$

a. Wilayah Surabaya
Tabel 1

Peramalan trend Linier untuk Wilayah Surabaya (gd.Malang)

\begin{tabular}{|l|c|c|c|c|}
\hline \multicolumn{1}{|c|}{ Bulan } & Penj.(y) & $\mathbf{X}$ & $\mathbf{X . Y}$ & $\mathbf{X}^{\mathbf{2}}$ \\
\hline Agust '01 & 988 & -4 & -3952 & 16 \\
Sept'01 & 986 & -3 & -2958 & 9 \\
Okt '01 & 988 & -2 & -1976 & 4 \\
Nov'01 & 996 & -1 & -995 & 1 \\
Des'01 & 997 & 0 & 0 & 0 \\
Jan '02 & 996 & 1 & 996 & 1 \\
Febr '02 & 998 & 2 & 1996 & 4 \\
Maret '02 & 998 & 3 & 2997 & 9 \\
April '02 & 999 & 4 & 3996 & 16 \\
\hline Jumlah & $\mathbf{8 9 4 6}$ & $\mathbf{0}$ & $\mathbf{1 0 4}$ & $\mathbf{6 0}$ \\
\hline
\end{tabular}

$$
\begin{aligned}
& \mathrm{a}=\frac{8946}{9}=994 \\
& \mathrm{~b}=\frac{104}{60}=1,7
\end{aligned}
$$

Estimasi Bulan Mei ’02 - Juli '02 :

$$
\begin{array}{ll}
\mathrm{Y}^{\prime}{ }_{5}=\mathrm{a}+\mathrm{b} \cdot \mathrm{x} & =994+1,4 \cdot 5=1002,1 \\
\mathrm{Y}^{\prime}{ }_{6} & =994+1,4 \cdot 6=1004,4 \\
\mathrm{Y}^{\prime}{ }_{7} & =994+1,4 \cdot 7=1005,9
\end{array}
$$

b. Wilayah Sidoarjo (gd.Mlg)

Tabel 2

Peramalan trend Linier untuk Wilayah Sidoarjo (gd.Malang)

\begin{tabular}{|l|c|c|c|c|}
\hline \multicolumn{1}{|c|}{ Bulan } & Penj. (y) & $\mathbf{X}$ & $\mathbf{X . Y}$ & $\mathbf{X}^{\mathbf{2}}$ \\
\hline Agust '01 & 651 & -4 & -2572 & 16 \\
Sept'01 & 656 & -3 & -1974 & 9 \\
Okt '01 & 657 & -2 & -1314 & 4 \\
Nov'01 & 658 & -1 & -655 & 1 \\
Des'01 & 658 & 0 & 0 & 0 \\
Jan '02 & 659 & 1 & 659 & 1 \\
Febr '02 & 661 & 2 & 1322 & 4 \\
Maret '02 & 663 & 3 & 1989 & 9 \\
April '02 & 664 & 4 & 2656 & 16 \\
\hline Jumlah & $\mathbf{5 9 0 9}$ & $\mathbf{0}$ & $\mathbf{1 3 8}$ & $\mathbf{6 0}$ \\
\hline
\end{tabular}

$$
\begin{aligned}
& \mathrm{a}=\frac{5909}{9}=656.6 \\
& \mathrm{~b}=\frac{138}{60}=2.3
\end{aligned}
$$

Estimasi Bulan Mei '02 - Juli '02 :

$$
\begin{aligned}
\mathrm{Y}_{5}^{\prime}=\mathrm{a}+\mathrm{b} . \mathrm{x} & =656.6+2,3.5=1002,1 \\
\mathrm{Y}_{6}{ }_{6} & =656.6+2,3.6=1004,4
\end{aligned}
$$


$\mathrm{Y}^{\prime}{ }_{7}$

$$
=656.6+2,37=1005,9
$$

c. Wilayah Probolinggo (gd.Mlg)

Tabel 3

Peramalan trend Linier untuk Wilayah Probolinggo (gd.Malang)

\begin{tabular}{|c|c|c|c|c|}
\hline Bulan & Penj. (y) & $\mathbf{X}$ & $\mathbf{X . Y}$ & $\mathbf{X}^{\mathbf{2}}$ \\
\hline Agust '01 & 605 & -4 & -2420 & 16 \\
Sept'01 & 604 & -3 & -1812 & 9 \\
Okt '01 & 607 & -2 & -1214 & 4 \\
Nov '01 & 608 & -1 & -608 & 1 \\
Des'01 & 611 & 0 & 0 & 0 \\
Jan '02 & 609 & 1 & 60 & 1 \\
Febr '02 & 613 & 2 & 1226 & 4 \\
Maret '02 & 614 & 3 & 1842 & 9 \\
April '02 & 617 & 4 & 2468 & 16 \\
\hline Jumlah & $\mathbf{5 4 8 8}$ & $\mathbf{0}$ & $\mathbf{9 1}$ & $\mathbf{6 0}$ \\
\hline
\end{tabular}

$$
\begin{aligned}
& \mathrm{a}=\frac{5488}{9}=609,8 \\
& \mathrm{~b}=\frac{91}{60}=1,52
\end{aligned}
$$

Estimasi Bulan Mei '02 - Juli '02 :

$\mathrm{Y}^{\prime}{ }_{5}=\mathrm{a}+\mathrm{b} \cdot \mathrm{x}=609,8+1 \cdot 52 \cdot 5=$

617.3

$\begin{array}{ll}\mathrm{Y}^{\prime}{ }_{6} & =609.8+1.52 .6=618.8 \\ \mathrm{Y}^{\prime}{ }_{7} & =609.8+1.52 .7=620.3\end{array}$

\section{Peramalan Menggunakan Metode Trend}

\section{Eksponensial}

$\log Y^{\prime}=a \cdot b^{x}$

$\log Y^{\prime}=\log a+x \log b$

Dimana $: \log a=\frac{\sum \log y}{n}$

$\log b=\frac{\sum(x \cdot \log y)}{\sum x^{2}}$

a. Peramalan untuk Wilayah Surabaya

Tabel 4

Peramalan Trend Eksponensial untuk Wilayah Surabaya (gd.Malang)

\begin{tabular}{|c|c|c|c|c|c|}
\hline Bulan & Penj.y) & Log. Y & $\mathbf{X}$ & $\mathbf{X . \operatorname { l o g } . \mathbf { Y }}$ & $\mathbf{X}^{\mathbf{2}}$ \\
\hline Agust '01 & 988 & 2.9948 & -4 & -11.9792 & 16 \\
Sept'01 & 986 & 2.9938 & -3 & -8.9814 & 9 \\
Okt '01 & 988 & 2.9948 & -2 & -5.9896 & 4 \\
Nov'01 & 995 & 2.9978 & -1 & -2.9978 & 1 \\
Des'01 & 997 & 2.9987 & 0 & 0 & 0 \\
Jan'02 & 996 & 2.9983 & 1 & 2.9983 & 1 \\
Febr '02 & 998 & 2.9991 & 2 & 5.9982 & 4 \\
Maret '02 & 999 & 2.9996 & 3 & 8.9988 & 9 \\
April '02 & 999 & 2.9996 & 4 & 11.9984 & 16 \\
\hline Jumlah & $\mathbf{8 9 4 6}$ & $\mathbf{2 6 . 9 7 6 5}$ & $\boldsymbol{0}$ & $\mathbf{0 . 0 4 5 7}$ & $\mathbf{6 0}$ \\
\hline
\end{tabular}

$$
\begin{aligned}
& \mathrm{a}=\frac{26.9765}{9}=2.9974 \\
& \mathrm{~b}=\frac{0.0457}{60}=0.00076
\end{aligned}
$$

Estimasi Bulan Mei '02 - Juli '02 : $\mathrm{y}_{5}=1002.76$

$\log \mathrm{Y}_{6}{ }_{6}=2.9974+0.00076 .5=3.00196$ , $\mathrm{y}=1004.52$

$\log \mathrm{Y}_{7}{ }_{7}=2.9974+0.00076 .5=$ $3.00272, y=1006.28$

$\log \mathrm{Y}_{5}{ }_{5}=\mathrm{a}+\mathrm{b} \cdot \mathrm{x}=2.9974+0.00076 .5=$ 3.0012 
b. Wilayah Sidoarjo (gd.Mlg)

Tabel 5

Peramalan Trend Eksponensial untuk Wilayah Sidoarjo (gd.Malang)

\begin{tabular}{|c|c|c|c|c|c|}
\hline Bulan & Penj. (y) & $\log \mathbf{y}$ & $\mathbf{X}$ & $\mathbf{X} . \log \mathbf{Y}$ & $\mathbf{X}^{\mathbf{2}}$ \\
\hline Agust '01 & 643 & 2.8082 & -4 & -11.2328 & 16 \\
Sept'01 & 649 & 2.8122 & -3 & -8.4366 & 9 \\
Okt 01 & 657 & 2.8176 & -2 & -5.6352 & 4 \\
Nov'01 & 655 & 2.8162 & -1 & -2.8182 & 1 \\
Des'01 & 658 & 2.8182 & 0 & 0 & 0 \\
Jan'02 & 659 & 2.8189 & 1 & 2.8189 & 1 \\
Febr '02 & 661 & 2.8202 & 2 & 5.6404 & 4 \\
Maret '02 & 663 & 2.8215 & 3 & 8.4645 & 9 \\
April '02 & 664 & 2.8222 & 4 & 11.2888 & 16 \\
\hline Jumlah & $\mathbf{5 9 0 9}$ & $\mathbf{2 5 . 3 5 5 2}$ & $\mathbf{0}$ & $\mathbf{0 . 0 8 9 8}$ & $\mathbf{6 0}$ \\
\hline
\end{tabular}

$$
\begin{aligned}
& \mathrm{a}=\frac{25.3552}{9}=2.8172 \\
& \mathrm{~b}=\frac{0.0898}{60}=0.00149
\end{aligned}
$$

Estimasi Bulan Mei ’02 - Juli ‘02 : $\log \mathrm{Y}_{5}{ }_{5}=\mathrm{a}+\mathrm{b} . \mathrm{x}=2.8172+0.001495=$ $2.8247, \mathrm{y}_{5}=667.8$

$\log \mathrm{Y}_{6}{ }_{6}=2.8172+0.00149 .6=2.8261$ , $y=670.1$

$\log \mathrm{Y}_{7}^{\prime}=2.8172+0.00149 .7=2.8276$ ,y $=672.4$

c. Peramalan untuk wilayah Probolinggo (gd.Mlg)

Tabel 6

Peramalan Trend Ekponensial untuk Wilayah Probolinggo (gd.Malang)

\begin{tabular}{|l|c|c|c|c|c|}
\hline \multicolumn{1}{|c|}{ Bulan } & Penj. (y) & Log Y & $\mathbf{X}$ & $\mathbf{X . ~} \mathbf{L o g} \mathbf{Y}$ & $\mathbf{X}^{\mathbf{2}}$ \\
\hline Agust '01 & 605 & 2.7818 & -4 & -11.1270 & 16 \\
Sept'01 & 604 & 2.7810 & -3 & -8.3431 & 9 \\
Okt '01 & 607 & 2.7832 & -2 & -5.664 & 4 \\
Nov'01 & 608 & 2.7839 & -1 & -2.7839 & 1 \\
Des'01 & 611 & 2.7864 & 0 & 0 & 0 \\
Jan'02 & 609 & 2.7846 & 1 & 2.7846 & 1 \\
Febr '02 & 613 & 2.7875 & 2 & 5.5749 & 4 \\
Maret '02 & 614 & 2.7882 & 3 & 8.3645 & 9 \\
April '02 & 617 & 2.7903 & 4 & 11.1611 & 16 \\
\hline \multicolumn{1}{|l}{ Jumlah } & $\mathbf{5 4 8 8}$ & $\mathbf{2 5 . 0 6 6 6}$ & $\mathbf{0}$ & $\mathbf{0 . 0 6 4 9}$ & $\mathbf{6 0}$ \\
\hline
\end{tabular}

$$
\begin{aligned}
& \mathrm{a}=\frac{25.0666}{9}=2.7852 \\
& \mathrm{~b}=\frac{0.0649}{60}=0.000108
\end{aligned}
$$

$\log \mathrm{Y}_{6}{ }_{6}=2.7852+0.0001086=$ $2.8261, \mathrm{y}=670.1$

$\log \mathrm{Y}_{7}{ }_{7}=2.7852+0.000108 \cdot 7=2.8276$ , $\mathrm{y}=610.88$

Estimasi Bulan Mei ’02 - Juli '02 :

$\log \mathrm{Y}^{\prime}{ }_{5}=\mathrm{a}+\mathrm{b} . \mathrm{x}=2.7852+0.000108 .5$

$=2.7857, \quad y_{5}=610.58$ 


\section{Pemilihan Metode Peramalan yang} Terbaik

Untuk menentukan metode peramalan yang lebih sesuai dari metode yang dipakai, disini penyusun menggunakan Mean Absolute Percentage Error ( MAPE ) sebagai ukuran dalam menentukan kesalahan. Untuk menghitung nilai MAPE, penyusun menggunakan program minitab. Kemudian yang memiliki nilai MAPE terkecil adalah metode yang digunakan untuk meramalkan permintaan.

Rumus Mean Absolute Percentage Error adalah (E.S Buffa,hal:74) :

$$
\text { MAPE }=\frac{1}{N} \sum_{t=1}^{N}\left|\frac{e_{t}}{d t} x 100\right|
$$

Ringkasan hasil - hasil perhitungan MAPE (Mean Absolute Percentage Error) dari program minitab , dapat dilihat pada tabel berikut :

\section{Tabel 7}

Perbandingan Mean Absolute Percentage Error

\begin{tabular}{|c|c|c|}
\hline $\begin{array}{c}\text { Wilayah } \\
\text { Pemasaran }\end{array}$ & $\begin{array}{c}\text { Metode } \\
\text { Trend Linier }\end{array}$ & $\begin{array}{c}\text { Metode } \\
\text { Trend Eksponensial }\end{array}$ \\
\hline Surabaya & 0.169 & 0.169 \\
Sidoarjo & 0.279 & 0.254 \\
Probolinggo & 0.164 & 0.137 \\
Banyuwangi & 0.183 & 0.184 \\
Situbondo & 0.128 & 0.129 \\
Ponorogo & 0.096 & 0.095 \\
Tulungagung & 0.043 & 0.043 \\
Bondowoso & 0.066 & 0.066 \\
Mojokerto & 0.079 & 0.079 \\
\hline
\end{tabular}

Dari hasil perbandingan mean absolute percentage error (MAPE) dari kedua metode peramalan yaitu Metode Trend Linier dan Trend Eksponensial, maka nilai MAPE yang terkecil (minimum) adalah Metode Trend Eksponential, jadi metode ini digunakan sebagai perhitungan peramalan permintaan.

\section{Hasil Peramalan}

Dalam menghitung ramalan permintaan periode yang akan datang, penyusun menggunakan data-data permintaan bulanan, dan hasilnya dapat ditabelkan sebagai berikut :

\section{Tabel 8}

Hasil Ramalan Permintaan (gd.Malang) Mei - Juli 2002

\begin{tabular}{|l|c|c|c|c|}
\hline \multicolumn{1}{|c|}{ Tujuan } & Mei & Juni & Juli & TOTAL \\
\hline Surabaya & 1002 & 1004 & 1006 & 3012 \\
\hline Sidoarjo & 668 & 670 & 672 & 2010 \\
\hline Probolinggo & 617 & 618 & 620 & 1855 \\
\hline Banyuwangi & 490 & 492 & 494 & 1476 \\
\hline Situbondo & 894 & 896 & 898 & 2688 \\
\hline Ponorogo & 844 & 846 & 847 & 2537 \\
\hline Tulungagung & 640 & 641 & 641 & 1922 \\
\hline Bondowoso & 873 & 874 & 875 & 2622 \\
\hline Mojokerto & 801 & 803 & 804 & 2408 \\
\hline TOTAL & 6829 & 6844 & 6857 & 20530 \\
\hline
\end{tabular}

Tabel 9

Hasil Ramalan Permintaan

(gd.Mojokerto)

Mei - Juli 2002

\begin{tabular}{|l|c|c|c|c|}
\hline \multicolumn{1}{|c|}{ Tujuan } & Mei & Juni & Juli & TOTAL \\
\hline Surabaya & 966 & 969 & 971 & 2906 \\
\hline Sidoarjo & 699 & 701 & 702 & 2102 \\
\hline Probolinggo & 486 & 487 & 488 & 1461 \\
\hline Banyuwangi & 501 & 503 & 504 & 1508 \\
\hline Situbondo & 802 & 804 & 805 & 2411 \\
\hline Ponorogo & 739 & 740 & 740 & 2219 \\
\hline Tulungagung & 602 & 603 & 603 & 1808 \\
\hline Bondowoso & 697 & 697 & 698 & 2092 \\
\hline Mojokerto & 740 & 741 & 742 & 2223 \\
\hline TOTAL & 6232 & 6245 & 6253 & 18730 \\
\hline
\end{tabular}

\section{Biaya Pengiriman Dalam Pola Jalur Distribusi}

Biaya pengiriman yang dibutuhkan untuk pengiriman setiap dus dari gudang ke lokasi pemasaran adalah berdasar biaya pengiriman yang ditetapkan perusahaan untuk tiap rute dibagi kapasitas angkut 
mobil dari tim ekspedisi. Jenis kendaraan yang digunakan adalah mobil Box dengan kapasitas angkut untuk tiap mobil sejumlah 30 dus.

Tabel 10

Biaya Transportasi (dalam ribuan /dus )

\begin{tabular}{|l|l|c|c|}
\hline Dari & \multicolumn{1}{|c|}{ Ke } & $\begin{array}{c}\text { Biaya } \\
\text { Distribusi }\end{array}$ & $\begin{array}{c}\text { Biaya } \\
\text { pengiriman /dus }\end{array}$ \\
\hline \multirow{5}{*}{ Malang } & Surabaya & 114.000 & 3800 \\
\cline { 2 - 4 } & Sidoarjo & 108.000 & 3600 \\
\cline { 2 - 4 } & Probolinggo & 171.000 & 5700 \\
\cline { 2 - 4 } & Banyuwangi & 381.000 & 12700 \\
\cline { 2 - 4 } & Situbondo & 315.000 & 10500 \\
\cline { 2 - 4 } & Ponorogo & 253.500 & 8450 \\
\cline { 2 - 4 } & Tulungagung & 115.500 & 3850 \\
\cline { 2 - 4 } & Bondowoso & 297.000 & 9900 \\
\cline { 2 - 4 } & Mojokerto & 121.500 & 4050 \\
\hline \multirow{5}{*}{ Mojokerto } & Surabaya & 72.000 & 2400 \\
\cline { 2 - 4 } & Sidoarjo & 117.000 & 3900 \\
\cline { 2 - 4 } & Probolinggo & 192.000 & 6400 \\
\cline { 2 - 4 } & Banyuwangi & 355.500 & 11850 \\
\cline { 2 - 4 } & Situbondo & 294.000 & 9800 \\
\cline { 2 - 4 } & Ponorogo & 282.000 & 9400 \\
\cline { 2 - 4 } & Tulungagung & 135.000 & 4500 \\
\cline { 2 - 4 } & Bondowoso & 277.500 & 9250 \\
\cline { 2 - 4 } & Mojokerto & 24.000 & 800 \\
\hline \multirow{5}{*}{ Probolinggo } & Situbondo & 72.000 & 2400 \\
\cline { 2 - 4 } & Bondowoso & 111.000 & 3700 \\
\cline { 2 - 4 } & Banyuwangi & 147.000 & 4900 \\
\hline Situbondo & Bondowoso & 39.000 & 1300 \\
\cline { 2 - 4 } & Banyuwangi & 67.500 & 2250 \\
\hline Surabaya & Sidoarjo & 36.000 & 1200 \\
\cline { 2 - 4 } & Tulungagung & 126.000 & 4200 \\
\hline \multirow{3}{*}{ Sidoarjo } & Tulungagung & 99.000 & 3300 \\
\cline { 2 - 4 } & Probolingo & 97.500 & 3250 \\
\cline { 2 - 4 } & Ponorogo & 165.000 & 2750 \\
\hline Tulungagung & Ponorogo & 66.000 & \\
\hline Bondowoso & Banyuwangi & 82.500 & \\
\hline \multirow{5}{*}{} & & & \\
\hline
\end{tabular}

\section{Pola Jalur Distribusi Awal}

Pola jalur distribusi yang ada pada perusahan saat ini masih belum optimum, karena setiap kebutuhan di lokasi pemasaran dipenuhi oleh ke-2 gudang dengan nilai sesuai masing-masing permintaan sehingga rute yang adapun tidak terkoordinasi dengan baik yang mengakibatkan tingginya biaya pengiriman.

\section{Perencanaan Pola Jalur Distribusi} dengan Metode Transhipment

Dengan memperhatikan hal yang ada di perusahaan tersebut, maka penulisan skripsi ini bertujuan untuk memberikan alternatif pola jalur distribusi dengan metode transshipment agar didapat biaya pengiriman total yang optimum. Perhitungan transshipment diselesaikan dengan menggunakan metode VAM sebagai solusi awal kemudian dilanjutkan menggunakan 
metode MODI untuk penentuan solusi optimal.

\section{Perbandingan biaya total sebelum dan sesudah analisa}

Perbandingan biaya pendistribusian produk Rokok harmonis adalah sebagai berikut :

* Total biaya pendistribusian sebelum analisa (dari perusahaan) :

a. TC (Gd. Malang)

$$
=(12700 \times 1476)+(8450 \times 2537)
$$$$
+(4050 \times 2408)+(3800 \times 3012)
$$$$
+(3600 \times 2010)+(3850 \times 1922)
$$$$
+(5700 \times 1855)+(10500 \times 2688)
$$

$+(9900 \times 2622)$

$=\operatorname{Rp} 140.771 .850$,-

b. TC (Gd. Mojokerto)

$$
\begin{aligned}
& =(11850 \times 1508)+(9400 \times 2219 \\
& )+(800 \times 2223)+(2400 \times 2906) \\
& +(3900 \times 2102)+(4500 \times 1808) \\
& +(6400 \times 1461)+(9800 \times 2411) \\
& +(9250 \times 2091) \\
& =\operatorname{Rp~} 109.160 .550,-
\end{aligned}
$$

Jadi total biaya yang harus dikeluarkan oleh perusahaan adalah jumlah biaya dari kedua sumber yaitu sebesar : Rp. 249.932.400,-

* Total biaya pendistribusian setelah analisa dengan menggunakan metode Transhipment

$$
\begin{aligned}
& \mathrm{TC}=(5700 \times 11399)+(2400 \times \\
& 8083)+(2250 \times 2984)+(3850 \times \\
& 8486)+(2200 \times 4756)+(3600 \times \\
& 645)+(2400 \times 9385)+(1200 \times \\
& 3467)+(9250 \times 4714)+(800 \times \\
& 4631) \\
& \text { TC }=\text { Rp } 210.537 .504,00
\end{aligned}
$$

\section{Penghematan biaya sebelum dan sesudah analisa}

Penentuan hasil distribusi optimal dibandingkan dengan distribusi awal setelah penerapan metode transshipment adalah untuk mengetahui besarnya penghematan yang terjadi.

Tabel 11

Biaya sebelum dan Sesudah Analisa

\begin{tabular}{|c|c|c|c|}
\hline Merk & Sebelum & Sesudah & Penghematan \\
\hline Harmonis & $\mathrm{Rp} 249.932 .400,00$ & $\mathrm{Rp} 210.537 .504,00$ & $\mathrm{Rp} \mathrm{39.394.896,00}$ \\
\hline
\end{tabular}

\section{KESIMPULAN}

Berdasarkan hasil analisa dan perencanaan yang telah dilakukan, maka dapat diambil kesimpulan :

1. Dari perhitungan yang dilakukan setelah penerapan model Transhipment menghasilkan pola distribusi yang optimal dengan biaya pengiriman yang minimum

2. Jumlah produk yang akan dialokasikan untuk tiap-tiap rute distribusi yang optimal adalah :

* Dari Malang ke Probolinggo sebesar 11399 Dus 
* Dari Malang ke Tulungagung sebesar 8486 Dus

Dari Malang ke Sidoarjo sebesar 645 Dus

* Dari Mojokerto ke Surabaya sebesar 9385 Dus

* Dari Mojokerto ke Mojokerto sebesar 4631 Dus

* Dari Mojokerto ke Bondowoso sebesar 4714 Dus

* Dari Probolinggo ke Situbondo sebesar 8083 Dus

* Dari Situbondo ke Banyuwangi sebesar 2984 Dus

* Dari Tulungagung ke Ponorogo sebesar 4756 Dus

Dari Surabaya ke Sidoarjo sebesar 3467 Dus

3. Total biaya awal sebelum analisa sebesar Rp 249.932.400,00 dan total biaya sesudah analisa adalah sebesar Rp 210.537.504,00. Penghematan biaya yang diperoleh untuk pengiriman produk Rokok harmonis sebelum dan sesudah analisa adalah :

Rp 249.932.400,00 - $R p$ $210.537 .504,00=\operatorname{Rp} 39.394 .896,00$ Dengan prosentase penghematan sebesar $16 \%$.

\section{DAFTAR PUSTAKA}

Basu Swasta DH , 1988 , Metode Kuantitatif untuk Manajemen (Management Science / Operations Research), Edisi - Pertama, Liberty Yogyakarta
Buffa , Elwood S , 1985 , Manajemen Operasi dan Produksi Modern, Penerbit PT. Gramedia, Jakarta

Dimyati, Tjutju T, 1994, Operation

Research, Model - Model

Pengambilan Keputusan , Sinar

Baru, Bandung

Hillier, Frederick S , 1994 , Pengantar

Riset Operasi, Erlangga, Jakarta

Kotler, Philip, 1995, Manajemen

Pemasaran, Analisis, Perencanaan

Implementasi dan Pengendalian,

Prentice Hall, Jakarta

Makridakis, Spyros, 1995, Metode dan

Aplikasi Peramalan, Erlangga ,

Jakarta

Pangestu Subagyo, Marwan Asri dan T .

Hani Handoko , 1985 , Dasar -

dasar Operations Research, Edisi -

Kedua , BPFE UGM , Yogyakarta

Salim H.A Abbas 1998 , Manajemen

Transportasi , PT . Raja Grafindo

Perkasa , Jakarta

Siagian P , 1987, Penelitian Operasi Teori dan Praktek, Cetakan Pertama, UI

Press, Jakarta 